\title{
Tin-Doped Indium Oxide-Titania Core-Shell Nanostructures for Dye-Sensitized Solar Cells
}

\author{
Luping Li, ${ }^{1}$ Cheng Xu, ${ }^{1,2}$ Yang Zhao, ${ }^{1}$ and Kirk J. Ziegler ${ }^{1,2}$ \\ ${ }^{1}$ Department of Chemical Engineering, University of Florida, Gainesville, FL 32611, USA \\ ${ }^{2}$ Department of Materials Science \& Engineering, University of Florida, Gainesville, FL 32611, USA \\ Correspondence should be addressed to Kirk J. Ziegler; kziegler@che.ufl.edu
}

Received 10 November 2014; Revised 8 December 2014; Accepted 9 December 2014; Published 30 December 2014

Academic Editor: Ram N. P. Choudhary

Copyright (c) 2014 Luping Li et al. This is an open access article distributed under the Creative Commons Attribution License, which permits unrestricted use, distribution, and reproduction in any medium, provided the original work is properly cited.

\begin{abstract}
Dye-sensitized solar cells (DSSCs) hold great promise in the pursuit of reliable and cheap renewable energy. In this work, tindoped indium oxide (ITO)- $\mathrm{TiO}_{2}$ core-shell nanostructures are used as the photoanode for DSSCs. High-density, vertically aligned ITO nanowires are grown via a thermal evaporation method and $\mathrm{TiO}_{2}$ is coated on nanowire surfaces via $\mathrm{TiCl}_{4}$ treatment. It is found that high $\mathrm{TiO}_{2}$ annealing temperatures increase the crystallinity of $\mathrm{TiO}_{2}$ shell and suppress electron recombination in the core-shell nanostructures. High annealing temperatures also decrease dye loading. The highest efficiency of 3.39\% is achieved at a $\mathrm{TiO}_{2}$ annealing temperature of $500^{\circ} \mathrm{C}$. When $\mathrm{HfO}_{2}$ blocking layers are inserted between the core and shell of the nanowire, device efficiency is further increased to $5.83 \%$, which is attributed to further suppression of electron recombination from ITO to the electrolyte. Open-circuit voltage decay (OCVD) measurements show that the electron lifetime increases by more than an order of magnitude upon $\mathrm{HfO}_{2}$ insertion. ITO-TiO 2 core-shell nanostructures with $\mathrm{HfO}_{2}$ blocking layers are promising photoanodes for DSSCs.
\end{abstract}

\section{Introduction}

Dye-sensitized solar cells (DSSCs) have attracted a lot of attention in recent years due to their promising properties, including low cost, ease of fabrication, and flexibility in material selection $[1,2]$. A DSSC typically consists of a dyed $\mathrm{TiO}_{2}$-based photoanode, a platinized counter electrode, and a liquid electrolyte containing a redox couple (such as $\mathrm{I}^{-} / \mathrm{I}_{3}{ }^{-}$). Under illumination, electrons in the dye are excited from the HOMO to the LUMO level. These electrons are then injected into the conduction band of $\mathrm{TiO}_{2}$. A transparent conduction oxide (TCO) collects these electrons, which pass through the external circuit and generate power.

$\mathrm{TiO}_{2}$ nanoparticle-based thin films are conventionally used as the photoanode of DSSCs. $\mathrm{TiO}_{2}$ nanoparticles provide large surface area for maximum dye attachment, which enables high current densities and high efficiencies. However, electrons in $\mathrm{TiO}_{2}$ nanoparticles are transported via random walk [3-5], which limits the effective thickness of the $\mathrm{TiO}_{2}$ thin film to be $\sim 10 \mu \mathrm{m}$ [6]. The slow kinetics also leads to major electron losses via electron recombination from $\mathrm{TiO}_{2}$ to the electrolyte, from $\mathrm{TiO}_{2}$ to the dye, and from $\mathrm{TCO}$ to the electrolyte. Electron recombination is the limiting factor for increasing the efficiencies of DSSCs [7].

Core-shell nanostructures can be used to facilitate electron transport and suppress electron recombination. For instance, in $\mathrm{ITO}-\mathrm{TiO}_{2}$ core-shell nanostructures, the accumulation of positive and negative charges in the space-charge layers in the $\mathrm{TiO}_{2}$ shell establishes an electric field $[3,6,8-10]$, which could draw electrons in the $\mathrm{TiO}_{2}$ layer towards the ITO core during DSSC operation. The rapid transport of electrons in $\mathrm{TiO}_{2}$ could greatly suppress electron recombination from $\mathrm{TiO}_{2}$ to the electrolyte. The direct contact between the singlecrystalline ITO nanowires and the current collector ensures efficient electron collection as well.

Establishing compact blocking layers in the photoanode is also an effective approach to reducing electron recombination [11]. $\mathrm{TiO}_{2}$ has a bandgap of $3.2 \mathrm{eV}$ [12]; therefore, the high bandgap of $\mathrm{HfO}_{2}[7,13], \mathrm{Al}_{2} \mathrm{O}_{3}[14-16], \mathrm{SiO}_{2}[14,17]$, and $\mathrm{ZrO}_{2}[18]$ (typically $>5 \mathrm{eV}$ ) creates an energy barrier. This energy barrier acts as a blocking layer to electron transport that suppresses electron recombination with the electrolyte. 
However, the blocking layers need to be extremely thin $(<\mathrm{a}$ few $\mathrm{nm}$ ) so that forward electron transport is minimally impacted.

In this study, DSSCs based on $\mathrm{ITO}^{-\mathrm{TiO}_{2}}$ core-shell nanostructures are investigated. Vertically aligned ITO nanowires are grown directly on ITO/glass substrates by a thermal evaporation method. Core-shell nanostructures are formed by coating the nanowires with $\mathrm{TiO}_{2}$ through $\mathrm{TiCl}_{4}$ treatment. $\mathrm{HfO}_{2}$ blocking layers are deposited on ITO nanowire surfaces by atomic layer deposition (ALD). Photovoltaic properties of devices based on these core-shell nanostructures are evaluated.

\section{Experimental Section}

2.1. ITO Nanowire Growth. ITO nanowires were grown using a thermal evaporation method. Tin (99.995\%) and indium (99.99\%) powders were mixed in a $4.5: 10$ atomic ratio by a spatula. The mixed powder was loaded into the center of a quartz tube on a quartz boat. Glass slides with a predeposited 400-nm-thick ITO thin film (Thin Film Devices, Inc., USA) were coated with a $3 \mathrm{~nm}$ Au film by a sputter coater (Electron Microscopy Sciences, Inc., USA). The glass slides were placed a few centimeters from the metal source. A $0.5 \%$ oxygen gas stream (balance argon) was fed into the quartz tube at a flow rate of 50 standard cubic centimeters per minute ( $\mathrm{sccm})$. The vacuum level in the quartz tube was maintained below 170 mTorr for successful nanowire growth. The tube furnace was heated to $750^{\circ} \mathrm{C}$ for $30 \mathrm{~min}$ and cooled down. After each growth, scanning electron microscopy (SEM) was used to examine the nanowires. All nanowires used in this work have a length of $15 \pm 1 \mu \mathrm{m}$.

2.2. ITO-TiO ${ }_{2}$ Core-Shell Nanostructures. For maximum dye attachment, the nanowire surfaces were coated with a layer of $\mathrm{TiO}_{2}$ by $\mathrm{TiCl}_{4}$ treatment, resulting in ITO-TiO${ }_{2}$ coreshell nanostructures. Nanowires were immersed in a $0.1 \mathrm{M}$ $\mathrm{TiCl}_{4}$ solution for $8 \mathrm{~h}$ and this process was repeated 12 times. After coating, $\mathrm{TiO}_{2}$ was annealed at temperatures between 350 and $600^{\circ} \mathrm{C}$ for $1 \mathrm{~h}$ in air. To investigate the effect of blocking layers on device performance, a compact layer of $\mathrm{HfO}_{2}$ was deposited on nanowire surfaces by atomic layer deposition (ALD) before $\mathrm{TiCl}_{4}$ treatment. Tetrakis(dimethylamido)hafnium and $\mathrm{H}_{2} \mathrm{O}$ were the $\mathrm{Hf}$ and $\mathrm{O}$ sources for ALD, respectively. The nominal thickness of $\mathrm{HfO}_{2}$ for each ALD cycle is $0.11 \mathrm{~nm}$ and a total of 16 ALD cycles were performed on nanowire surfaces.

2.3. DSSC Device Fabrication. N719 dye (Dyesol) was dissolved in ethanol to make a $3 \mathrm{mM}$ solution. The annealed core-shell structures were soaked in dye solution for $\sim 14 \mathrm{~h}$ for dye attachment. Counter-electrode solution (CELS, Dyesol) was spin-coated on ITO/glass and annealed at $430^{\circ} \mathrm{C}$ for $10 \mathrm{~min}$. The core-shell nanostructure photoanode and the counter electrode were held together by clips with Scotch tape as the spacer. An $\mathrm{I}^{-} / \mathrm{I}_{3}{ }^{-}$solution was used as the electrolyte (EL-HPE, Dyesol).

2.4. Characterization. The morphologies and length of nanowires were examined by a SEM (FEI Nova NanoSEM
430). ITO- $\mathrm{TiO}_{2}$ core-shell structures were characterized by a JEOL 2010F transmission electron microscopy (TEM). The simulated global AM 1.5 spectrum $\left(100 \mathrm{~mW} \cdot \mathrm{cm}^{-2}\right)$ for device testing was produced by a light source (XPS 200 and 16s, Solar Light Company, USA). Current-voltage $(J-V)$ response and open-circuit voltage decay (OCVD) were recorded by a potentiostat (VersaSTAT 3, Princeton Applied Research, USA). For each type of cell, 3-4 devices were tested. OCVD measures the change of open-circuit voltage $\left(V_{\mathrm{oc}}\right)$ with time after illumination was interrupted. Electron lifetime $\left(\tau_{n}\right)$ was calculated from the slope of the decay curve [19], $\tau_{n}=$ $\left(-k_{B} T / e\right)\left(d V_{\mathrm{oc}} / d t\right)^{-1}$, where $k_{B}$ is the Boltzmann constant, $T$ is the absolute temperature, and $e$ is the positive electron charge. Dye loading was determined by desorbing the dye in $0.1 \mathrm{M} \mathrm{NaOH}$ water/ethanol $(1: 1 \mathrm{v} / \mathrm{v})$ solution and measuring its absorption spectrum using a Perkin-Elmer Lambda 800 UV-Vis spectrometer. The crystallinity of the $\mathrm{TiO}_{2}$ shell after annealing at different temperatures was investigated by a Renishaw inVia micro-Raman spectrometer equipped with a $785 \mathrm{~nm}$ laser.

\section{Results and Discussion}

Figure 1(a) shows the SEM image of ITO nanowires grown on ITO/glass substrate. When used as the photoanode, the vertically aligned nanowires are expected to efficiently transport electrons to the substrate where the current is collected. These nanowires have high density, which enables high dye loading and high current density during device operation. Figure 1(b) shows a TEM image of a nanowire coated with $\mathrm{TiO}_{2}$ by $\mathrm{TiCl}_{4}$ treatment. The radial electrical field in the ITO$\mathrm{TiO}_{2}$ core-shell structures could facilitate electron transport during DSSC operation by drawing electrons to the ITO core $[3,6]$.

Figure 2(a) shows the $J-V$ characteristics of devices without $\mathrm{HfO}_{2}$ blocking layers under illumination and Figure 2(b) at dark conditions when $\mathrm{TiO}_{2}$ was annealed between 350 and $600^{\circ} \mathrm{C}$. The corresponding photovoltaic properties are listed in Table 1 . It is seen that both open-circuit voltage $\left(V_{\mathrm{oc}}\right)$ and short-circuit current $\left(J_{\mathrm{sc}}\right)$ increase with the increase of annealing temperatures, which resulted in the highest efficiency of $3.39 \%$ when the annealing temperature for $\mathrm{TiO}_{2}$ shell was $500^{\circ} \mathrm{C}$. The increase in efficiency is attributed to two reasons. (a) Higher annealing temperatures resulted in better crystallinity of the anatase $\mathrm{TiO}_{2}$ shell, as evidenced by the Raman spectra of samples annealed at different temperatures shown in Figure 3. The better crystallinity led to better conductivity and charge transport. (b) Higher annealing temperatures suppressed electron recombination from ITO to the electrolyte, as evidenced by the smaller dark current in Figure 2(b). It should be noted that when compared to conventional $\mathrm{TiO}_{2}$ nanoparticle-based DSSCs, electron recombination from $\mathrm{TiO}_{2}$ to the electrolyte in ITO$\mathrm{TiO}_{2}$ core-shell nanostructures is minimized due to the rapid transport of electrons from $\mathrm{TiO}_{2}$ to ITO by the electric field in the $\mathrm{TiO}_{2}$ shell $[3,6]$.

At $600^{\circ} \mathrm{C}$, although the $V_{\text {oc }}$ continues to increase, the $J_{\mathrm{sc}}$ decreased dramatically, leading to a decreased device efficiency of $2.76 \%$. The decrease of efficiency is due to the 


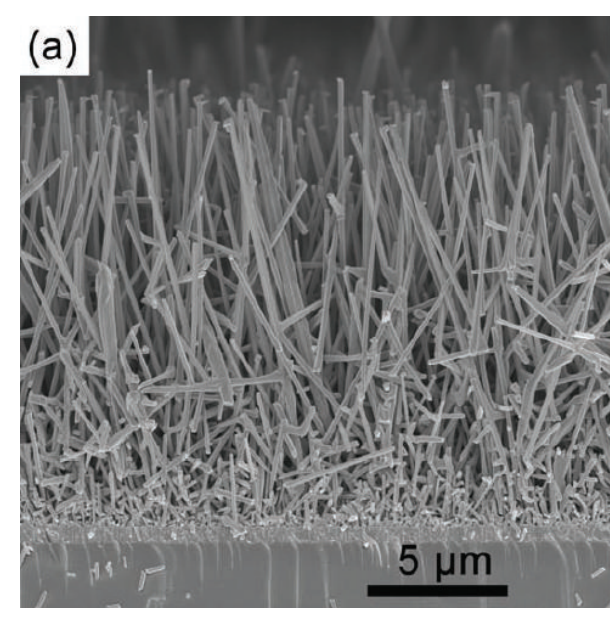

(a)

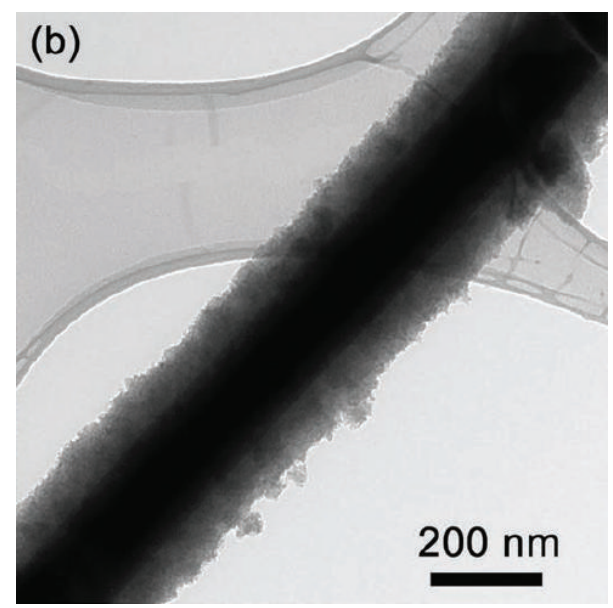

(b)

FIGURE 1: (a) SEM image of ITO nanowires grown by a thermal evaporation method and (b) TEM image of an ITO nanowire coated with $\mathrm{TiO}_{2}$ by $\mathrm{TiCl}_{4}$ treatment, forming an ITO- $\mathrm{TiO}_{2}$ core-shell nanostructure.

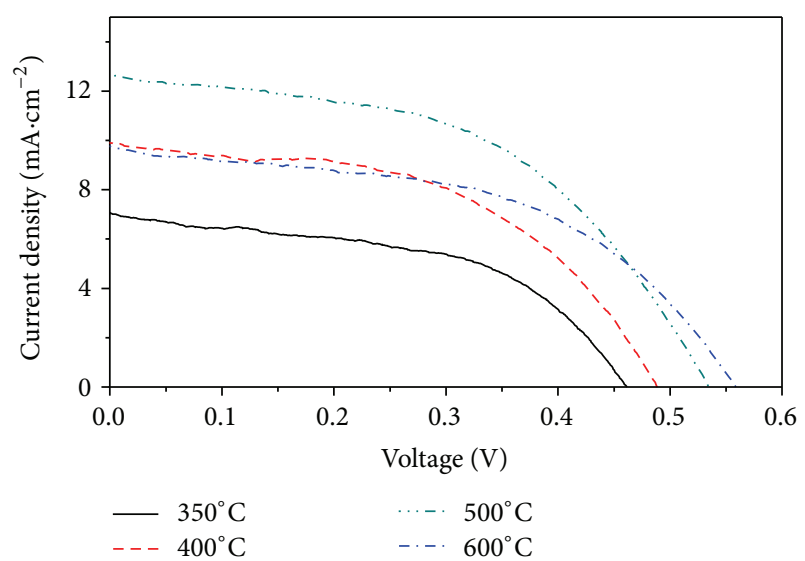

(a)

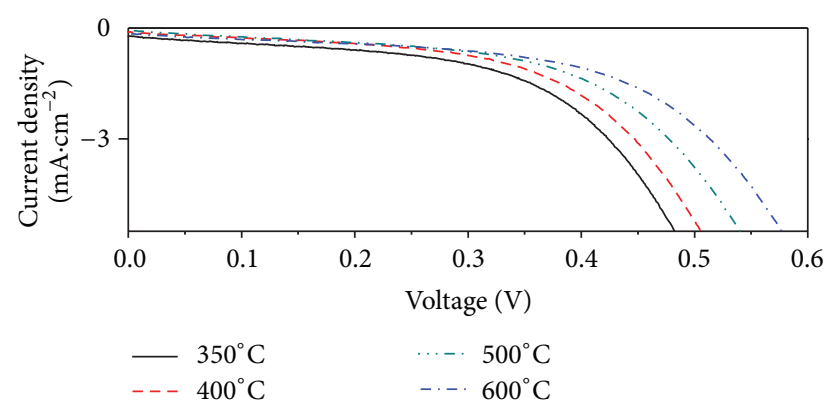

(b)

FIgURE 2: $J-V$ characteristics of devices when $\mathrm{TiO}_{2}$ shell was annealed between 350 and $600^{\circ} \mathrm{C}$ (a) under AM 1.5 illumination and (b) at dark condition.

decreased dye loading (see Table 1). The amount of dye loading directly dictates the current density in DSSCs. The decreased dye loading eventually resulted in lower efficiency despite the fact that the dark current continued to decrease at $600^{\circ} \mathrm{C}$, as shown in Figure 2(b).

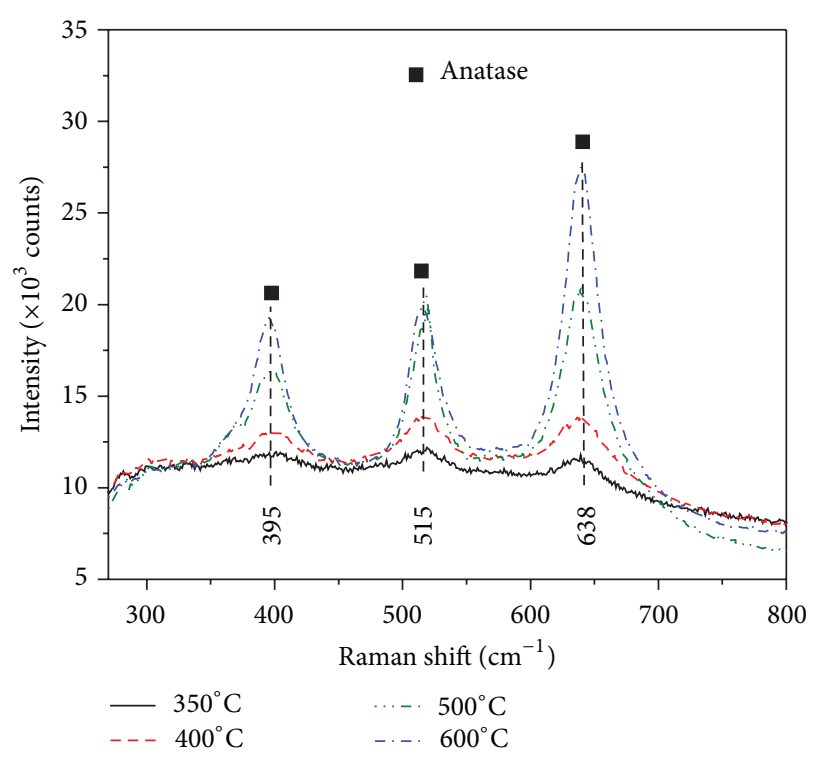

FIgURE 3: Raman spectra of $\mathrm{ITO}-\mathrm{TiO}_{2}$ core-shell nanostructures annealed between 350 and $600^{\circ} \mathrm{C}$.

To further improve DSSC efficiencies, compact $\mathrm{HfO}_{2}$ blocking layers were first deposited on nanowire surfaces. $\mathrm{TiCl}_{4}$ treatment was subsequently performed to form coreshell nanostructures, which were then annealed at $500^{\circ} \mathrm{C}$ for $1 \mathrm{~h} . J-V$ curves of the devices based on these structures are shown in Figure 4. Upon $\mathrm{HfO}_{2}$ insertion, the $V_{\mathrm{oc}}$ increased dramatically from 0.53 to $0.67 \mathrm{~V}$. The $V_{\text {oc }}$ of DSSCs is determined by the difference in Fermi level of $\mathrm{TiO}_{2}$ and that of the redox couple in the electrolyte [20]. Since the conduction band edge position for $\mathrm{HfO}_{2}$ is much higher than that for $\mathrm{TiO}_{2}$, the insertion of $\mathrm{HfO}_{2}$ between ITO and $\mathrm{TiO}_{2}$ could greatly raise the Fermi level of $\mathrm{TiO}_{2}$. Consequently, higher $V_{\mathrm{oc}}$ is seen in Figure 4(a).

The $\mathrm{HfO}_{2}$ blocking layer also greatly increased the $J_{\mathrm{sc}}$, as shown in Figure 4(a). From Table $2, \mathrm{HfO}_{2}$ barely affected 
TABLE 1: Photovoltaic properties of devices when the $\mathrm{TiO}_{2}$ shell was annealed between 350 and $600^{\circ} \mathrm{C}^{\mathrm{a}}$.

\begin{tabular}{lccccc}
\hline & $V_{\text {oc }}(\mathrm{V})$ & $J_{\text {sc }}\left(\mathrm{mA} \cdot \mathrm{cm}^{-2}\right)$ & FF $(\%)$ & $\eta(\%)$ & Dye loading $\left(\times 10^{-8} \mathrm{~mol} \cdot \mathrm{cm}^{-2}\right)$ \\
\hline $350^{\circ} \mathrm{C}$ & $0.46 \pm 0.03$ & $7.05 \pm 0.07$ & $50.7 \pm 1.0$ & $1.65 \pm 0.07$ & 2.16 \\
$400^{\circ} \mathrm{C}$ & $0.49 \pm 0.06$ & $9.90 \pm 0.08$ & $50.6 \pm 0.9$ & $2.45 \pm 0.08$ & 1.80 \\
$500^{\circ} \mathrm{C}$ & $0.53 \pm 0.03$ & $12.61 \pm 0.05$ & $50.7 \pm 0.6$ & $3.39 \pm 0.05$ & 1.32 \\
$600^{\circ} \mathrm{C}$ & $0.56 \pm 0.04$ & $9.75 \pm 0.05$ & $50.5 \pm 0.9$ & $2.76 \pm 0.07$ & 1.01 \\
\hline
\end{tabular}

${ }^{\text {a }}$ Average values and standard deviations are based on 3-4 devices.

TABLE 2: Photovoltaic properties of devices before and after the insertion of a compact $\mathrm{HfO}_{2}$ blocking layer by ALD .

\begin{tabular}{lccccc}
\hline & $V_{\mathrm{oc}}(\mathrm{V})$ & $J_{\mathrm{sc}}\left(\mathrm{mA} \cdot \mathrm{cm}^{-2}\right)$ & $\mathrm{FF}(\%)$ & $\eta(\%)$ & Dye loading $\left(\times 10^{-8} \mathrm{~mol} \cdot \mathrm{cm}^{-2}\right)$ \\
\hline Without $\mathrm{HfO}_{2}$ & $0.53 \pm 0.03$ & $12.61 \pm 0.05$ & $50.7 \pm 0.6$ & $3.39 \pm 0.05$ & 1.32 \\
With $\mathrm{HfO}_{2}$ & $0.67 \pm 0.05$ & $16.50 \pm 0.06$ & $52.7 \pm 0.9$ & $5.83 \pm 0.07$ & 1.36 \\
\hline
\end{tabular}

${ }^{a}$ Average values and standard deviations are based on 3-4 devices.

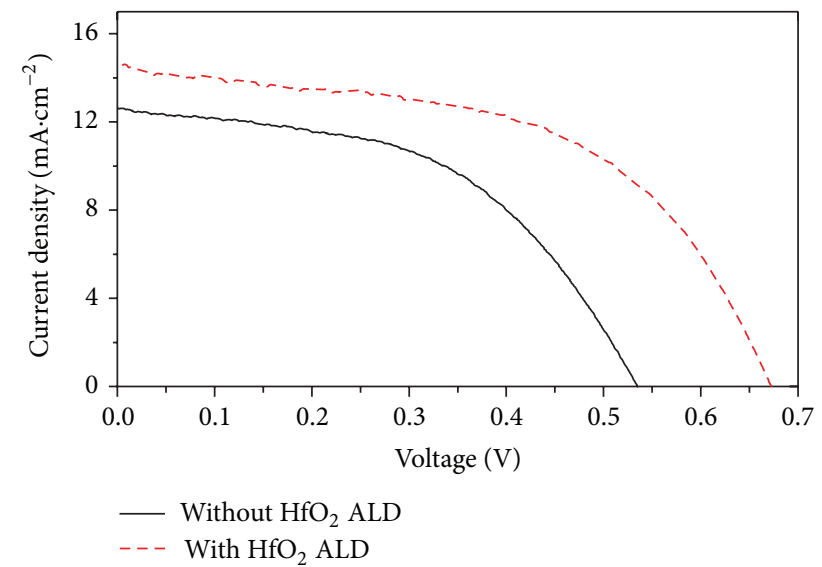

(a)

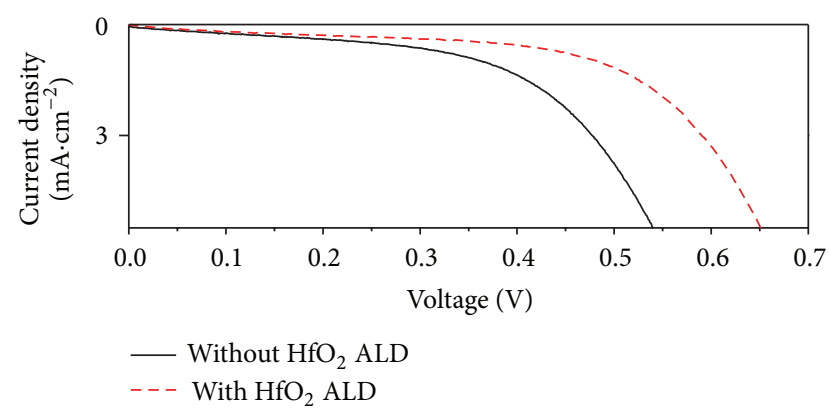

(b)

FIGURE 4: $J-V$ characteristics of devices before and after the insertion of a compact $\mathrm{HfO}_{2}$ blocking layer by ALD (a) under AM 1.5 illumination and (b) at dark condition.

dye loading. Therefore, the increase in $J_{\mathrm{sc}}$ is mainly attributed to the suppression of electron recombination by $\mathrm{HfO}_{2}$, as indicated by the smaller dark current in Figure 4(b). The high bandgap of $\mathrm{HfO}_{2}(5.9 \mathrm{eV}$ versus $3.6 \mathrm{eV}$ for ITO [7]) created an energy barrier that suppressed the back transfer of electrons from ITO to the electrolyte, while electrons in $\mathrm{TiO}_{2}$ could tunnel through the thin layer of $\mathrm{HfO}_{2}$ to reach ITO [1]. The axial electrical field in the $\mathrm{TiO}_{2}$ shell expected for core-shell nanowires [6] should also assist in drawing electrons to the ITO core. The higher $V_{\text {oc }}$ and $J_{\text {sc }}$ eventually led to an efficiency of $5.83 \%$ with $\mathrm{HfO}_{2}$ insertion, corresponding to an increase of $72 \%$ from devices without $\mathrm{HfO}_{2}$.

In order to investigate the electron transfer kinetics in DSSCs, OCVD measurements were performed and the results are shown in Figure 5. From Figure 5(a), higher $\mathrm{TiO}_{2}$ annealing temperatures resulted in slower $V_{\mathrm{oc}}$ decay, which is indicated by a higher voltage at any given time in Figure 5(a). From Figure 5(b), longer electron lifetimes are observed at higher $\mathrm{TiO}_{2}$ annealing temperatures. The slower $V_{\text {oc }}$ decay and longer electron lifetimes are due to suppressed electron recombination at higher $\mathrm{TiO}_{2}$ annealing temperatures, as discussed above.

From Figure 5(b), the electron lifetime increased dramatically upon $\mathrm{HfO}_{2}$ deposition. For instance, when $\mathrm{TiO}_{2}$ was annealed at $500^{\circ} \mathrm{C}, \mathrm{HfO}_{2}$ deposition increased the electron lifetime by more than an order of magnitude from 0.031 to $0.38 \mathrm{~s}$ at $0.4 \mathrm{~V}$. The increased electron lifetime ultimately led to the increased efficiency as seen in Table 2.

\section{Conclusions}

In summary, ITO- $\mathrm{TiO}_{2}$ core-shell nanostructures are used as the photoanode of DSSCs. High-density, vertically aligned ITO nanowires are grown via a thermal evaporation method. Core-shell nanostructures are formed by coating the nanowires with $\mathrm{TiO}_{2}$ through $\mathrm{TiCl}_{4}$ treatment. $\mathrm{TiO}_{2}$ are annealed between 350 and $600^{\circ} \mathrm{C}$ and the photovoltaic properties of these devices are investigated. High annealing temperatures increase the crystallinity of the $\mathrm{TiO}_{2}$ shell and suppress electron recombination. High annealing temperatures also result in lower dye loading. The highest efficiency of $3.39 \%$ is achieved when $\mathrm{TiO}_{2}$ is annealed at $500^{\circ} \mathrm{C}$. Inserting $\mathrm{HfO}_{2}$ blocking layers on nanowire surfaces further suppresses electron recombination from ITO to the electrolyte and a maximum efficiency of $5.83 \%$ is achieved. OCVD measurements indicate that $\mathrm{HfO}_{2}$ blocking layers increase the electron lifetime by more than an order of magnitude.

\section{Conflict of Interests}

The authors declare that there is no conflict of interests regarding the publication of this paper. 


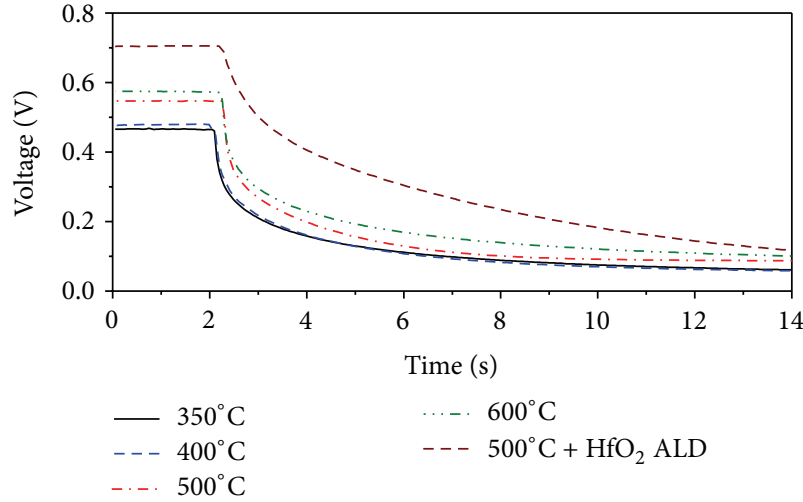

(a)

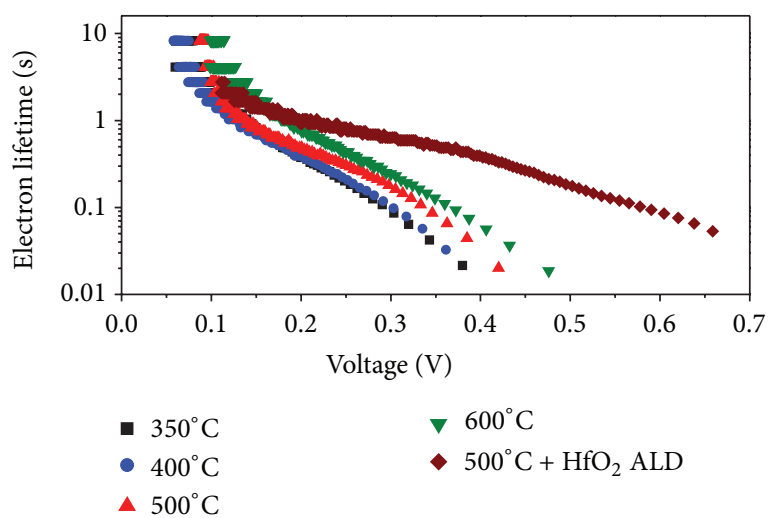

(b)

FIGURE 5: (a) Open-circuit voltage decay (OCVD) curves and (b) electron lifetimes of photoanodes annealed at temperatures between 350 and $600^{\circ} \mathrm{C}$.

\section{Acknowledgments}

The authors acknowledge the support of the Donors of the American Chemical Society Petroleum Research Fund, the University of Florida Opportunity Fund, and the National Science Foundation (CBET-1033736) for support of this research.

\section{References}

[1] A. K. Chandiran, N. Tetreault, R. Humphry-Baker et al., "Subnanometer $\mathrm{Ga}_{2} \mathrm{O}_{3}$ tunnelling layer by atomic layer deposition to achieve $1.1 \mathrm{v}$ open-circuit potential in dye-sensitized solar cells," Nano Letters, vol. 12, no. 8, pp. 3941-3947, 2012.

[2] L. Li, S. Chen, C. Xu et al., "Comparing electron recombination via interfacial modifications in dye-sensitized solar cells," ACS Applied Materials \& Interfaces, vol. 6, no. 23, pp. 20978-20984, 2014.

[3] M. Law, L. E. Greene, J. C. Johnson, R. Saykally, and P. Yang, "Nanowire dye-sensitized solar cells," Nature Materials, vol. 4, no. 6, pp. 455-459, 2005.

[4] L. Peter, "Transport, trapping and interfacial transfer of electrons in dye-sensitized nanocrystalline solar cells," Journal of Electroanalytical Chemistry, vol. 599, no. 2, pp. 233-240, 2007.

[5] L. M. Peter and K. G. U. Wijayantha, "Electron transport and back reaction in dye sensitized nanocrystalline photovoltaic cells," Electrochimica Acta, vol. 45, no. 28, pp. 4543-4551, 2000.

[6] J. J. Hill, N. Banks, K. Haller, M. E. Orazem, and K. J. Ziegler, "An interfacial and bulk charge transport model for dye-sensitized solar cells based on photoanodes consisting of core-shell nanowire arrays," Journal of the American Chemical Society, vol. 133, no. 46, pp. 18663-18672, 2011.

[7] B. Bills, M. Shanmugam, and M. F. Baroughi, "Effects of atomic layer deposited $\mathrm{HfO}_{2}$ compact layer on the performance of dyesensitized solar cells," Thin Solid Films, vol. 519, no. 22, pp. 78037808, 2011.

[8] A. Du Pasquier, H. Chen, and Y. Lu, "Dye sensitized solar cells using well-aligned zinc oxide nanotip arrays," Applied Physics Letters, vol. 89, no. 25, Article ID 253513, 2006.

[9] A. B. F. Martinson, J. E. McGarrah, M. O. K. Parpia, and J. T. Hupp, "Dynamics of charge transport and recombination in $\mathrm{ZnO}$ nanorod array dye-sensitized solar cells," Physical Chemistry Chemical Physics, vol. 8, no. 40, pp. 4655-4659, 2006.

[10] J. B. Baxter and E. S. Aydil, "Dye-sensitized solar cells based on semiconductor morphologies with $\mathrm{ZnO}$ nanowires," Solar Energy Materials and Solar Cells, vol. 90, no. 5, pp. 607-622, 2006.

[11] S. Zhang, X. Yang, C. Qin, Y. Numata, and L. Han, "Interfacial engineering for dye-sensitized solar cells," Journal of Materials Chemistry A, vol. 2, no. 15, pp. 5167-5177, 2014.

[12] Y. Xu and M. A. Schoonen, "The absolute energy positions of conduction and valence bands of selected semiconducting minerals," American Mineralogist, vol. 85, no. 3-4, pp. 543-556, 2000.

[13] P. Ramasamy, M.-S. Kang, H.-J. Cha, and J. Kim, "Highly efficient dye-sensitized solar cells based on $\mathrm{HfO}_{2}$ modified $\mathrm{TiO}_{2}$ electrodes," Materials Research Bulletin, vol. 48, no. 1, pp. 79-83, 2013.

[14] E. Palomares, J. N. Clifford, S. A. Haque, T. Lutz, and J. R. Durrant, "Control of charge recombination dynamics in dye sensitized solar cells by the use of conformally deposited metal oxide blocking layers," Journal of the American Chemical Society, vol. 125, no. 2, pp. 475-482, 2003.

[15] C. Lin, F.-Y. Tsai, M.-H. Lee et al., "Enhanced performance of dye-sensitized solar cells by an $\mathrm{Al}_{2} \mathrm{O}_{3}$ charge-recombination barrier formed by low-temperature atomic layer deposition," Journal of Materials Chemistry, vol. 19, no. 19, pp. 2999-3003, 2009.

[16] C. Prasittichai and J. T. Hupp, "Surface modification of $\mathrm{SnO}_{2}$ photoelectrodes in dye-sensitized solar cells: significant improvements in photovoltage via $\mathrm{Al}_{2} \mathrm{O}_{3}$ atomic layer deposition," The Journal of Physical Chemistry Letters, vol. 1, no. 10, pp. 1611-1615, 2010.

[17] M. Shanmugam, M. F. Baroughi, and D. Galipeau, "Effect of atomic layer deposited ultra thin $\mathrm{HfO}_{2}$ and $\mathrm{Al}_{2} \mathrm{O}_{3}$ interfacial layers on the performance of dye sensitized solar cells," Thin Solid Films, vol. 518, no. 10, pp. 2678-2682, 2010.

[18] T. C. Li, M. S. Góes, F. Fabregat-Santiago et al., "Surface passivation of nanoporous $\mathrm{TiO}_{2}$ via atomic layer deposition of $\mathrm{ZrO}_{2}$ for solid-state dye-sensitized solar cell applications," The Journal of Physical Chemistry C, vol. 113, no. 42, pp. 18385-18390, 2009. 
[19] A. Zaban, M. Greenshtein, and J. Bisquert, "Determination of the electron lifetime in nanocrystalline dye solar cells by opencircuit voltage decay measurements," ChemPhysChem, vol. 4, no. 8, pp. 859-864, 2003.

[20] S. R. Raga, E. M. Barea, and F. Fabregat-Santiago, "Analysis of the origin of open circuit voltage in dye solar cells," The Journal of Physical Chemistry Letters, vol. 3, no. 12, pp. 1629-1634, 2012. 

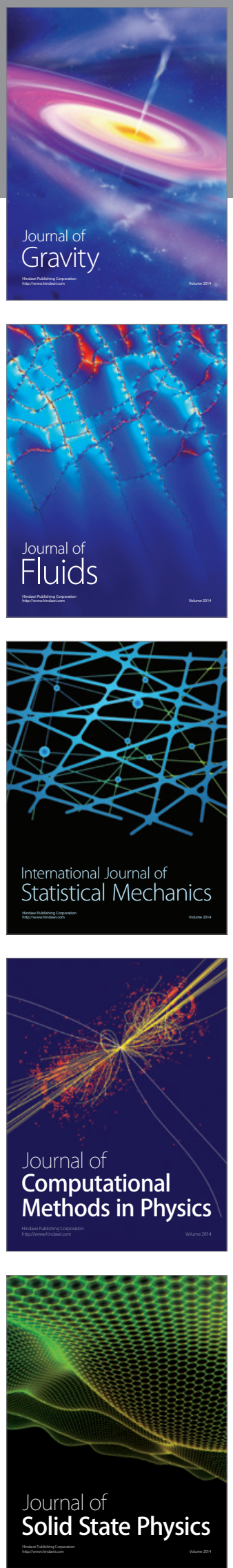

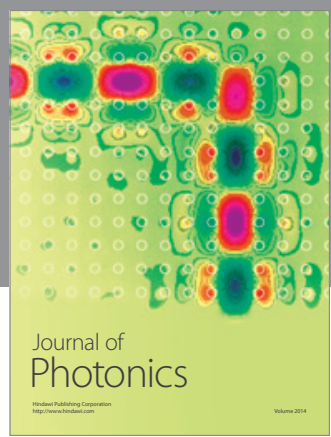

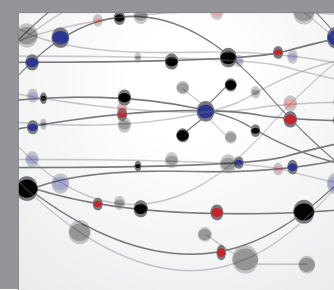

The Scientific World Journal

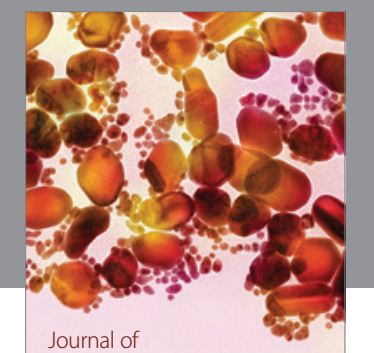

Soft Matter
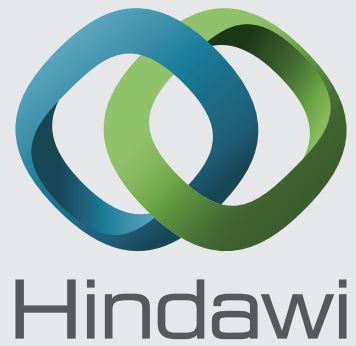

Submit your manuscripts at

http://www.hindawi.com
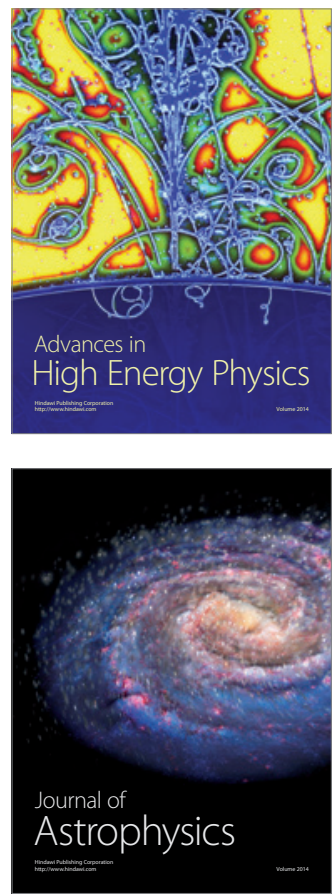
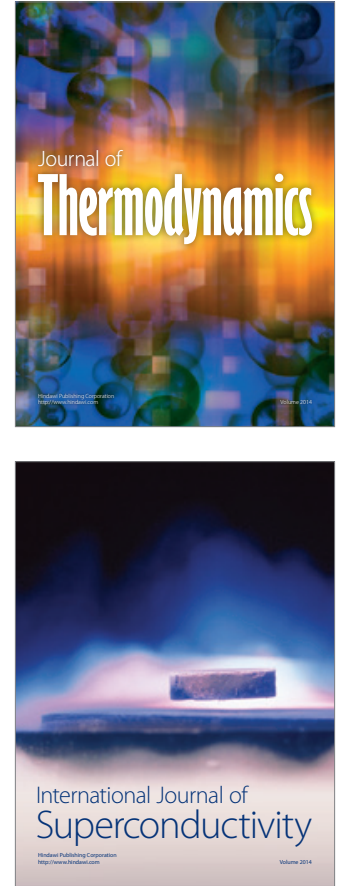
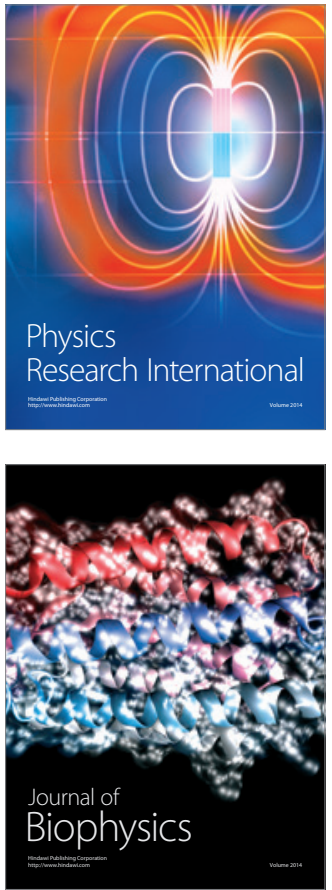
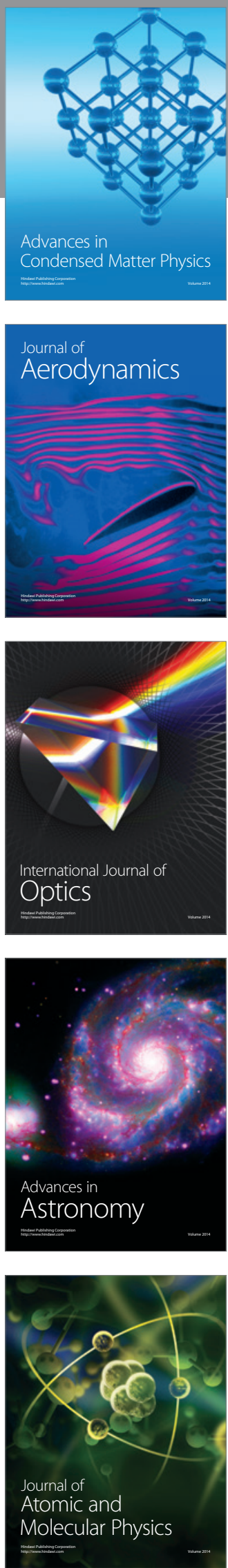